\title{
Correction to: What Eye Movements Can and Cannot Tell Us About Wh-Movement and Scrambling
}

Irina A. Sekerina, Anna K. Laurinavichyute and Olga Dragoy

Correction to:

Chapter "What Eye Movements Can and Cannot Tell Us About $W h$-Movement and Scrambling" in:

K. Carlson et al. (eds.), Grammatical Approaches

to Language Processing, Studies in Theoretical

Psycholinguistics 48,

https://doi.org/10.1007/978-3-030-01563-3_8

In the original version of the book, the incorrect co-author name "Olga Dragnoy" has to be corrected as "Olga Dragoy" in the chapter "What Eye Movements Can and Cannot Tell Us About Wh-Movement and Scrambling". The erratum chapter and the book have been updated with the change. 